\title{
WALO: Ferramenta para Gerenciamento de Mídias Sociais
}

\author{
Marília G. Santos \\ Instituto Federal da Bahia \\ R. Emídio dos Santos, Barbalho \\ Salvador, Bahia 40.301-015 \\ mariliasantos@ifba.edu.br
}

\author{
Antonio C. S. Souza \\ Instituto Federal da Bahia \\ R. Emídio dos Santos, Barbalho \\ Salvador, Bahia 40.301-015 \\ antoniocarlos@ifba.edu.br
}

\author{
Márcio C. F. Macedo \\ Universidade Federal da Bahia \\ Av. Adhemar de Barros, Ondina \\ Salvador, Bahia 40.170-110 \\ marcio.cerqueira@ufba.br
}

\begin{abstract}
Social media is a very important tool for businesses, especially those that depend on marketing strategies for greater brand recognition. In addition, social media helps enrich the customer experience and reduce marketing expenses. Social media management allows companies to get information that reflects the overall consumer sentiment of their brand or their products, quickly and securely. However, such management is not an easy task, since the large amount of existing social media requires a lot of effort from professionals to deal with all the information that influences these social media. Therefore, a reasonable need is identified in creating a specific tool to manage social media at once. In this article, we propose WALO, a new open source tool that allows professionals to use different social media simultaneously, providing a new way for these professionals to interact with their clients through a chatbot.
\end{abstract}

\section{KEYWORDS}

Social networks, social media management, open-source tool

\section{INTRODUÇÃO}

As mídias sociais possuem muito conteúdo, em virtude da troca de informações que é realizada a todo momento entre os usuários. As empresas estão gradativamente utilizando as mídias sociais para divulgar sua marca, porque assim é possível ter maior visibilidade no mercado com baixo custo, ou mesmo custo zero de investimento, já que as mídias sociais são ambientes propícios para a interação dos usuários com a marca [9].

Atualmente, há um custo elevado para construir uma marca com alta reputação na Internet, uma vez que é necessário planejamento estratégico de comunicação e marketing de modo que a marca se torne conhecida e tenha credibilidade. Eventualmente, durante esse processo, podem surgir solicitações e comentários desfavoráveis nas mídias sociais a respeito da empresa, devido às exigências dos consumidores, que sempre querem maiores detalhes das informações disponíveis a respeito da marca com menor tempo de resposta possível [5].

As empresas que planejam entrar no mundo virtual devem realizar um estudo, fazendo o levantamento das reais necessidades dos potenciais consumidores, a fim de transmitir segurança quanto à empresa e proporcionar uma melhor impressão sobre marca. Assim, tendo em vista que as empresas precisam acompanhar a sua

In: XV Workshop de Trabalhos de Iniciação Científica (WTIC 2018), Salvador, Brasil. Anais do XXIV Simpósio Brasileiro de Sistemas Multimídia e Web: Workshops e Pôsteres. Porto Alegre: Sociedade Brasileira de Computação, 2018.

(c) 2018 SBC - Sociedade Brasileira de Computação.

ISBN 978-85-7669-435-9. reputação nas mídias sociais, surge a necessidade do desenvolvimento de uma ferramenta com interface intuitiva e que viabilize o monitoramento da reputação da empresa de acordo com as manifestações (postagens, notificações, possíveis dúvidas) dos usuários nas mídias sociais.

De acordo com o exposto, propõe-se neste artigo uma ferramenta open-source para gerenciamento de mídias sociais que almeja possibilitar a comunicação de uma empresa com os seus potenciais clientes através de um chatbot, que terá como funções principais a análise dos comentários nas mídias sociais e a interação com os seus usuários, podendo então sanar dúvidas em comum, otimizando e diminuindo a quantidade de atendimentos realizados pelos colaboradores da empresa. Dessa forma, a ferramenta WALO permitirá o acompanhamento e a análise dos questionamentos realizados pelos clientes.

O restante deste artigo está estruturado da seguinte forma:

- A Seção 2 contém uma breve descrição dos trabalhos relacionados ao tema deste artigo. Nessa Seção é feita uma comparação entre o WALO e as ferramentas existentes tanto na literatura quanto na academia para o gerenciamento das mídias sociais;

- A Seção 3 apresenta a descrição da ferramenta open-source para gerenciamento de mídias sociais que é proposta neste artigo;

- Por fim, na Seção 4, são apresentadas as considerações finais do trabalho, bem como uma perspectiva de trabalhos futuros para o desenvolvimento e avaliação da ferramenta;

\section{TRABALHOS RELACIONADOS}

Nesta seção, serão apresentados alguns trabalhos relacionados ao tema proposto para o artigo.

Almeida et al. [2] abordam uma análise do impacto de diversos tipos de conteúdos acerca do marketing viral. Estas são técnicas de marketing que têm em vista explorar as mídias sociais com o propósito de obter uma maior repercussão da marca. Os autores utilizaram o Facebook para analisar oito perfis de marcas brasileiras de cerveja e seu impacto na rede social. Este artigo é relevante para o campo de análise de mídias sociais, uma vez que demonstra a influência das postagens em mídias sociais e no marketing das empresas.

Kim et al. [7] expressam uma visão geral do impacto da influência social e da tomada de decisões sobre o comércio eletrônico para conduzir os pesquisadores e empresas que têm interesse em questões relacionadas às mídias sociais. É possível capturar comportamentos dos clientes, da mesma maneira que a influência social pode ser usada pelo comércio eletrônico, e sites podem ser utilizados 
para auxiliar no processo de tomada de decisão dos potenciais consumidores. Os autores discutem que é necessário acompanhar a repercussão da marca nas mídias sociais e a importância de cada produto ou serviço nos comentários, tornando possível o acompanhamento imediato do que cada cliente pode estar comentando sobre a marca, o que pode influenciar no alcance de potenciais clientes.

Victória Aires, Fabiola Nakamura e Eduardo Nakamura [1] abordam o aproveitamento das redes sociais, tendo em vista que representam relações tanto de amizade quanto de trabalho. Os autores estudam se as redes sociais tem influência no sucesso de um filme. Para esse estudo, eles realizaram a análise das redes sociais de cinco filmes, a fim de apresentar resultados que comprovassem que o sucesso de bilheteria de um filme está associado ao sucesso que ele faz na rede social. Apesar dos resultados terem sido positivos, o estudo realizado consistiu apenas em uma análise introdutória acerca do tema, tendo em vista que há a necessidade da coleta de uma maior base de dados, possibilitando uma análise mais detalhada dos filmes em suas redes sociais.

$\mathrm{Na}$ indústria, já existem algumas ferramentas que auxiliam os usuários no gerenciamento de suas mídias sociais.

HootSuite [6] é uma ferramenta que auxilia a realização do gerenciamento das mídias sociais em uma única interface, viabilizando a criação de várias páginas de conteúdo personalizável. Em cada aba referente a uma mídia social, é possível adicionar diferentes colunas com o que é postado e recepcionado. Através do HootSuite, é possível programar a publicação de postagens, definindo a data, horário e o perfil em que se deseja realizar a publicação.

A ferramenta é bastante utilizada para o gerenciamento de vários perfis em uma mesma rede, possibilitando assim a realização de uma análise geral dos perfis, sem que seja necessário efetuar login/logout para cada conta. Sua interface é simples e proporciona agilidade e pleno controle do que acontece nas mídias sociais, permitindo que seja avaliado como, por quem e quando a informação for recebida.

Esta ferramenta é a mais próxima da proposta deste trabalho, porém possui três desvantagens: (i) a interface é confusa para quem necessita gerenciar vários perfis da mesma mídia social; (ii) a versão gratuita só permite o gerenciamento de até três perfis; (iii) é necessária a realização de um pagamento para se obter um relatório de análise mais detalhado. Enquanto isso, a WALO se propõe a ser uma ferramenta open-source, que não oferece nenhum custo ao usuário, assim como possui uma interface intuitiva, de fácil compreensão e visualização das publicações no painel de monitoramento.

Postcron [8] é uma das ferramentas mais conhecidas no mercado quando o assunto é agendamento de publicações no Facebook. É um aplicativo que permite agendamento de forma rápida, em várias mídias sociais. Outra grande vantagem é a sua extensão integrada ao Chrome, que facilita o agendamento de publicações, porém são limitadas às possíveis mídias sociais que podem ser integradas, assim como há um custo alto a ser investido para aquisição, e os valores variam de acordo com a quantidade de contas, postagens e quantidade de analistas de mídias sociais que gerirão a ferramenta.

Buffer [4] é uma ferramenta para gerenciamento de mídias sociais voltada para os analistas da área. Essa ferramenta possui diversas funcionalidades para auxiliar no gerenciamento dos perfis, além disso, a ferramenta oferece uma variedade de aplicativos mobile e extensões de navegador, possibilitando adicionar conteúdo ao mesmo tempo em que os analistas de mídias sociais vão descobrindo o perfil. O Buffer é uma ferramenta intuitiva, o que torna fácil disseminar conteúdos nas mídias sociais, porém nas versões em que há mais funcionalidades existem limitações, uma vez que a ferramenta não é open source. A ferramenta não permite interação direta com os utilizadores, e sua versão gratuita tem recursos bastante limitados.

Tendo em vista os trabalhos e ferramentas listados, a WALO, além de realizar o gerenciamento das mídias sociais, tem como diferencial a varredura nos comentários realizados pelos potenciais clientes, de modo que as dúvidas possam ser sanadas pelo botWalo, que será inicializado a partir do reconhecimento de alguma palavra informada nos comentários, que já estará cadastrada na base de conhecimento do bot, podendo assim diminuir a quantidade de acionamentos a um humano.

\section{WALO}

O objetivo da WALO é realizar, através da ferramenta open-source, o gerenciamento de mídias sociais, de forma que a própria comunidade possa agregar novas funcionalidades no projeto de forma extensível e transparente. A plataforma visa facilitar o gerenciamento e monitoramento das marcas de diferentes empresas nas mídias sociais, sanando o maior número possível de questionamentos publicados por potenciais clientes, de forma que a empresa possa prestar melhor suporte e retorno mais rápido para o cliente. A partir dessa interação rápida e eficaz, em que a empresa esclarece a dúvida do cliente, a marca da empresa é fortalecida no mercado, pois quanto menor o tempo de resposta de cada solicitação, maior credibilidade as empresas ganham frente às mídias sociais.

A finalidade do uso do chatbot na ferramenta é auxiliar o usuário no esclarecimento de suas dúvidas. Para tanto, o chatbot realiza seu processamento baseado em palavras já cadastradas numa base de dados. O chatbot tem como propósito diminuir a necessidade de acionamento de um humano para responder questionamentos que se repetem nas mídias sociais. Porém, o cliente ainda poderá solicitar contato com um colaborador da empresa a qualquer momento, durante a interação com o botWalo. Isso porque, na WALO, o chatbot não se passará por um humano, apenas tentará esclarecer a dúvida do cliente de forma rápida e objetiva.

Além do que já foi exposto, a ferramenta possibilita que o usuário realize uma nova postagem na WALO e visualize essa postagem na mídia social escolhida, bem como a busca das postagens.

Para o desenvolvimento da ferramenta, foram escolhidas duas redes sociais: Facebook e Twitter, já que elas fazem parte das redes sociais mais acessadas no mundo [3].

Para auxiliar na implantação do chatbot na WALO foi utilizado o Dialogflow ${ }^{1}$, que é um pacote de desenvolvimento da Google, criado para desenvolver interfaces de tecnologias de interação humanocomputador baseadas em recursos de processamento de linguagem natural, que serão adicionadas aos aplicativos, serviços e dispositivos. Fazendo uso da tecnologia de aprendizagem de máquina, o Dialogflow reconhece a intenção e o contexto da fala de um usuário, de modo que na comunicação o bot possa oferecer respostas eficientes e precisas.

\footnotetext{
${ }^{1}$ https://dialogflow.com/
} 
As áreas de conhecimento do BotWalo foram definidas em duas possibilidades: a do conhecimento específico e a do conhecimento adicional. A área de conhecimento específico possui informações já cadastradas, vinculadas aos produtos e serviços expostos nas redes sociais. A base de conhecimento foi extraída dos comentários de clientes nas redes sociais antes do desenvolvimento da ferramenta. O BotWalo não foi desenvolvido com o propósito de se passar por um humano, por isso a área de conhecimento adicional é captada pelo usuário administrador da ferramenta, através dos dados estatíticos extraídos da ferramenta, notificando a quantidade de chamados atendidos pelo humano e a quantidade de chamados atendidos através do BotWalo. Caso a quantidade de atendimentos realizados pelo BotWalo seja maior que aquela realizada pelo humano, a área de conhecimento do BotWalo está atendendo às expectativas, caso contrário será necessário adicionar informações ao bot, de modo que ele esteja o mais completo possível e consiga sanar o maior número de questionamentos realizados pelos clientes.

\subsection{Levantamento de Requisitos}

Nesta seção são apresentadas todas as condições que foram definidas como requisitos funcionais e não funcionais relevantes para a construção da ferramenta proposta.

3.1.1 Requisitos Funcionais. Através dos requisitos funcionais são descritas as funcionalidades e serviços desenvolvidos no sistema. $\mathrm{Na}$ tabela 1 são listados os requisitos funcionais.

3.1.2 Requisitos não funcionais. O conjunto de requisitos não funcionais do sistema estão listados logo abaixo.

Usabilidade. A ferramenta proposta deve ser simples e de fácil utilização;

Manutenibilidade. A ferramenta proposta deve possibilitar reparos de forma facilitada, bem como a inclusão de novas funcionalidades, visando assim o aperfeiçoamento do software.

Desempenho. A plataforma desenvolvida deve buscar identificar, nos possíveis comentários dos clientes, dúvidas que possam ser sanadas através do chatbot, que verifica periodicamente as novas mensagens, a fim de proporcionar maior rapidez no tempo de resposta.

Portabilidade. Por se tratar de um sistema web, a ferramenta desenvolvida deve ser portável, podendo ser utilizada em navegadores e sistemas operacionais distintos.

Segurança. A ferramenta deve oferecer segurança por meio de autenticação ao sistema;

\subsection{Arquitetura do Sistema}

A arquitetura da WALO é formada por três camadas, explicitando o padrão arquitetural MVC (Model-View-Controller ou Modelo-ControleVisão), o qual viabiliza a independência dos dados trabalhados e das ações do moderador que necessita desses dados.

A camada Model fica encarregada da lógica e inteligência do sistema, da validação de negócio e processamento. A camada View se encarrega da parte da aplicação que interage com o usuário moderador, nesta camada é dada visibilidade para os componentes na apresentação dos dados. Já a camada Controller se encarrega
Table 1: Requisitos funcionais estabelecidos para o WALO.

\begin{tabular}{|l|l|}
\hline No $^{\circ}$ & Requisitos \\
\hline RF1 & $\begin{array}{l}\text { O Usuário deve ser capaz de monitorar pelo menos uma } \\
\text { mídia social através ferramenta; }\end{array}$ \\
\hline RF2 & $\begin{array}{l}\text { A ferramenta tem apenas um perfil de usuário mod- } \\
\text { erador, o qual deve moderar e liderar as possíveis dis- } \\
\text { cussões realizando todo o acompanhamento das mídias } \\
\text { sociais; }\end{array}$ \\
\hline RF3 & $\begin{array}{l}\text { O usuário autenticado deve visualizar e responder aos } \\
\text { comentários dos potenciais clientes; }\end{array}$ \\
\hline RF4 & $\begin{array}{l}\text { Cada mídia social monitorada deve exibir as postagens } \\
\text { com suas respectivas curtidas e comentários; }\end{array}$ \\
\hline RF5 & $\begin{array}{l}\text { O sistema deve verificar as postagens dos clientes, de } \\
\text { modo a identificar possíveis dúvidas e questionamentos; }\end{array}$ \\
\hline RF6 & $\begin{array}{l}\text { O sistema deve exibir a postagem inicialmente em for- } \\
\text { mato sintetizado; }\end{array}$ \\
\hline RF7 & $\begin{array}{l}\text { O sistema deve possibilitar a interação com as mídias } \\
\text { sociais através do chatbot quando houver algum ques- } \\
\text { tionamento acerca dos seus projetos; }\end{array}$ \\
\hline RF8 & $\begin{array}{l}\text { O sistema deve permitir que o moderador responda aos } \\
\text { questionamentos dos clientes nas redes sociais, caso } \\
\text { não obtenha resposta através do chatbot; }\end{array}$ \\
\hline RF10 & $\begin{array}{l}\text { O sistema deve exibir gráficos com a quantidade de } \\
\text { solicitações respondidas pelo chatbot e avaliação do } \\
\text { chatbot pelo humano; } \\
\text { as mídias sociais a cerca dos seus produtos; }\end{array}$ \\
\hline
\end{tabular}

de receber as requisições do usuário moderador, a qual interage com a view que monta os objetos correspondentes e passa-os à camada Model para executar a solicitação. A WALO possibilita a incorporação de novas redes sociais, através da chamada do metódo require na classe Monitoramento. A Figura 1 apresenta a arquitetura do botWalo. Através dele os usuários podem ter respostas aos seus questionamentos de forma mais rápida e objetiva. O sistema principal é expresso através da compreensão da linguagem, acesso e recuperação das informações, e do controlador de conversões. O sistema também é conectado através de uma fonte de dados, que realiza armazenamento das respostas para as perguntas mais frequentes, popularmente conhecidas como FAQs ( Frequently Asked Questions).

Language Understanding. O desafio associado ao uso do botWalo está relacionado à area de PLN (Processamento de Linguagem Natural), uma vez que uma limitação da identificação das palavras mais utilizadas nas redes sociais impede que botWalo seja acionado de forma apropriada para interação com o usuário. Para tanto, FAQs serão armazenadas numa base de dados, para que o bot consiga identificar as perguntas e responder seus cliente. Para os questionamentos que não podem ser respondidos através do botWalo, também há armazenamento no banco de dados do registro de conversas, de modo que sejam analisados para inserção de novas FAQs. Isso permite que haja uma diminuição das solicitações dos clientes para realizar contato com um humano. 


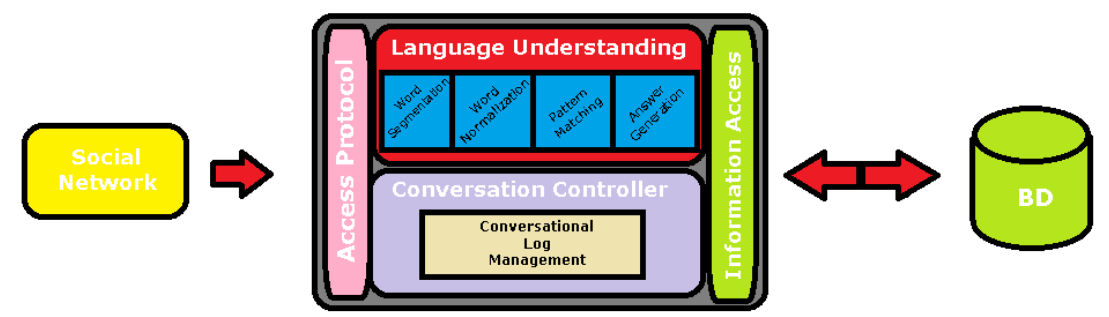

Figure 1: Arquitetura Model Viewer Controller

Conversation Controller. O controlador de conversão fornece a qualidade de serviço adequada para as sessões, bem como permite que se entenda o que cada cliente questiona e que se mantenha os arquivos de $\log$ da conversação. Esta função consiste em gerenciar os logs de conversas onde há todos os registros de conversas entre os usuários e o sistema. Através desses registros é possível analisar questões específicas caso o sistema não esteja fornecendo algum tipo de resposta. Além disso, este módulo fornece algumas estatísticas: (i) número de usuários que deram like numa postagem, (ii) quantidade de acionamentos do botWalo, (iii) solicitações de direcionamento para falar com um humano, (iv) quantidade perguntas ainda desconhecidas pelo bot Walo.

\section{CONCLUSÃO E TRABALHOS FUTUROS}

Neste artigo, foi apresentada a proposta da WALO: uma ferramenta para gerenciamento de mídias sociais, que tem como finalidade auxiliar os analistas da área no monitoramento das redes sociais, bem como, na busca de possíveis questionamentos publicados. A fim de esclarecer estas dúvidas, almeja-se o uso de um chatbot na WALO. Com o intuito de ajudar os profissionais que utilizam as mídias sociais para divulgação da marca, a plataforma disporá de um processo centralizado e automatizado na busca de possíveis questionamentos dos potenciais clientes. Visando otimizar a centralização dos questionamentos dos clientes em uma única plataforma, já que as discussões ocorrem em mídias distintas, este artigo mostra uma possível solução para agregar várias mídias sociais em uma plataforma.

Como trabalhos futuros, almeja-se o desenvolvimento e lançamento da ferramenta WALO para o público em geral, adicionando o suporte ao monitoramento de várias mídias sociais, o suporte à postagem de conteúdos multimídias nas mídias sociais de forma programada, bem como a integração dos chatbots à plataforma, para auxílio no controle da reputação da marca da empresa na Internet.

\section{REFERÊNCIAS}

[1] Victória P. Aires, Fabíola G. Nakamura, and Eduardo F. Nakamura. 2017. A Social Network Analysis of Successful Movies with Complex Networks. In Proceedings of the 23rd Brazillian Symposium on Multimedia and the Web: Workshops and Posters. 99-102.

[2] Marcos Inácio Severo de Almeida, Milena Costa, Ricardo Limongi Franca Coelho, and Paulo Roberto Scalco. 2016. "Engaja-me e atraia-me, então eu compartilharei": uma análise do impacto da categoria da postagem no marketing viral em uma rede social. Revista Brasileira de Gestão de Negócios 18 (12 2016), 545 - 569.

[3] Fernanda Beling. 2016. As 10 maiores redes sociais. (2016). https://www. oficinadanet.com.br/post/16064-quais-sao-as-dez-maiores-redes-sociais [Online; accessed 18-julho-2018].

[4] Buffer. 2018. Buffer. https://buffer.com/. (2018). Accessed: 2018-07-30

[5] Yany Grégoire, Audrey Salle, and Thomas M Tripp. 2015. Managing social media crises with your customers: The good, the bad, and the ugly. Business Horizons 58, 2 (2015), 173-182.

[6] HootSuite. 2018. HootSuite. https://hootsuite.com. (2018). Accessed: 2018-07-30.

[7] Young Ae Kim and Jaideep Srivastava. 2007. Impact of Social Influence in eCommerce Decision Making. In Proceedings of the Ninth International Conference on Electronic Commerce. ACM, New York, NY, USA, 293-302.

[8] PostCron. 2018. PostCron. https://postcron.com. (2018). Accessed: 2018-07-30.

[9] Cong Qi and Patrick YK Chau. 2016. An Empirical Study of the effect of Enterprise Social Media Usage on Organizational Learning.. In Proceedings of PACIS. 330. 